\title{
Long term sport involvement and sport injury rate in elite young athletes
}

\author{
N Maffulli, A D G Baxter-Jones, A Grieve
}

Arch Dis Child 2005;90:525-527. doi: 10.1136/adc.2004.057653

M any young athletes have undergone years of intensive training by adolescence. ${ }^{12}$ Intensive training at a young age may cause long term harmful effects. ${ }^{3}$ Our longitudinal study on the effects of intensive training in young British athletes (TOYA study), which ran from 1987 to 1992, showed a low prevalence of sports injuries from 1988 to $1990 .{ }^{4}$ Most sports injuries were minor, and did not seem to cause significant short to medium term health problems. ${ }^{4}$ Given the possible interaction between intensive training and growth during adolescence, ${ }^{5-7}$ some adolescent athletes may be particularly vulnerable to repetitive microtraumatic injury. ${ }^{2}$ Despite the perceived benefits of early training on bone mass accumulation, ${ }^{8-10}$ intensive training may have detrimental effects on young athletes' growth, ${ }^{3}$ although these concerns are probably unfounded. ${ }^{2}{ }^{10-12}$ However, it is possible that the effects of training at a young age may not manifest themselves until later in life. To our knowledge, there are no long term studies in young adulthood of injuries prevalence or sports participation in athletes who started systematic training during or prior to adolescence. As we had already studied a unique population of intensively trained elite young athletes, we planned the present study to establish the frequency and pattern of injuries sustained by the cohort of young intensively trained young British athletes originally enrolled in the TOYA study, 10 years after completion of the survey.

\section{METHODS \\ TOYA study (1987-92)}

The Training of Young Athletes Study (TOYA) has been extensively described. ${ }^{43-15}$ In brief, the study used a mixed longitudinal design, taking annual measurements for three consecutive years from 1988 to 1990. Five age cohorts were used, with entry ages ranging from 8 to 16 years. During the course of the study the composition of these clusters remained the same; as there were overlaps between clusters, a consecutive 11 year development pattern (8 to 19 years) was established. In total, we recruited 453 subjects: 231 males ( 38 gymnasts, 65 soccer players, 54 swimmers, and 74 tennis player) and 222 females ( 81 gymnasts, 60 swimmers, and 81 tennis player). The study received ethical approval from the joint Hospital for Sick Children/Institute of Child Health Ethical Committee.

\section{TOYA follow up study (2000)}

The last known address of the parents of each of the 453 subjects of the original TOYA study was taken from a database held in the Department of Child Health, University of Aberdeen. Four athletes had retired before the end of the original TOYA study, and three mailing addresses were incomplete: 446 questionnaires were thus posted in the spring of 2000. Forty three questionnaires were returned as "addressees unknown" and were deducted from the denominator, giving a sample size of $403(44.8 \%$ of the original sample of 453 subjects). Four weeks after the initial mailing, non-respondents were posted a reminder letter. After the reminder letters the response rate was $38.2 \%$. Two weeks after the reminder letter mailing, non-respondents were contacted by telephone, and the response rate rose to $50.37 \%$.

\section{Subjects}

In total, 203 subjects completed and returned the questionnaires and constitute the sample in the present analysis. Ninety two males (15 gymnasts, 22 soccer players, 24 swimmers, and 31 tennis player) and 111 females (37 gymnasts, 33 swimmers, and 41 tennis player) responded.

\section{Questionnaire}

In the present study, the definition of "injury" was the same as the one given in the original TOYA study, ${ }^{4}{ }^{15}$ namely a musculoskeletal problem requiring reduction or interruption of the sports activity that the subjects were undertaking for any length of time, possibly with a request for professional advice.

The questions were modified from the semi-structured interviews that took place in the initial TOYA study, thus enabling comparisons between the two data sets. ${ }^{16}$ Current sports involvement (section A) was ascertained. Section B ascertained how many injuries the young athlete had suffered since 1990, and what treatment and recovery time had been required. Section C obtained anthropometric information including height and weight, and, in females only, additional questions regarding age of first menstrual period and the start date of their last menstrual period. In section $\mathrm{D}$, the young athletes were asked detailed questions regarding their overall sports performance and the level of

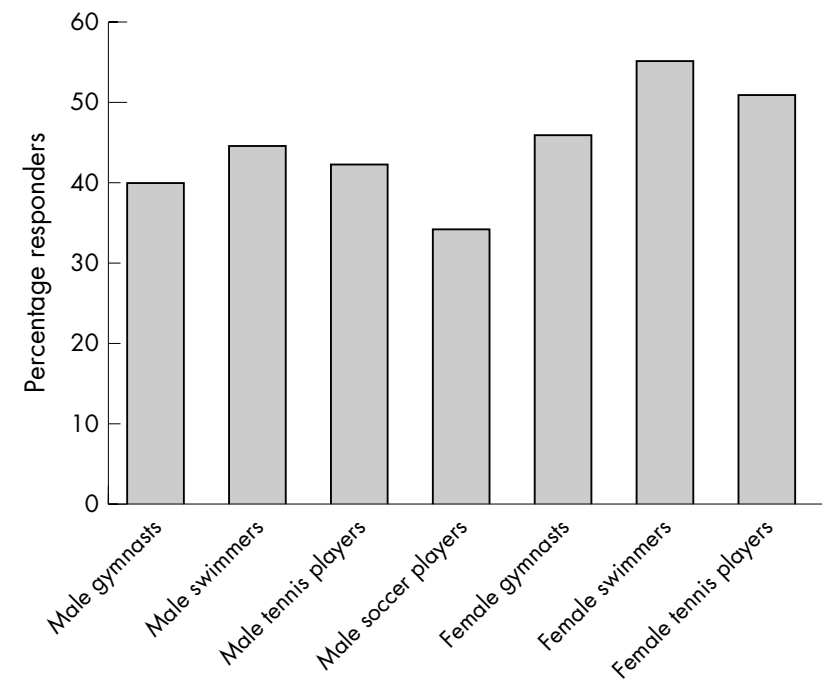

Figure 1 Distribution of responders from initial TOYA study by sex and sport. 
Table 1 Number of subjects injured between 1990 and 2000 by sport

\begin{tabular}{lll}
\hline & \multicolumn{2}{l}{ Sports injury } \\
\cline { 2 - 3 } Sport & No. & Yes \\
\hline Gymnastics & $25(48.1 \%)$ & $27(51.9 \%)$ \\
Swimming & $41(71.9 \%)$ & $16(28.1 \%)$ \\
Tennis & $36(50 \%)$ & $36(50 \%)$ \\
Soccer & $8(36.4 \%)$ & $14(63.6 \%)$ \\
\hline \multirow{2}{*}{ Values are number (percentage of sample). }
\end{tabular}

competition achieved. Section E asked detailed questions on each of the three injuries which they felt were the most important in the period 1990 to 2000.

\section{Data handling}

All returned questionnaires were valid and could be analysed. The data were coded and entered onto a database. Decimal age was calculated from date of measurement and date of birth. Injury location was grouped into upper limb, lower limb, and back.

Injury rates and locations were compared with those of the original TOYA study. $\chi^{2}$ analysis, and, where appropriate, $\chi^{2}$ tests for linear trends were performed. The data were analysed using the Statistical Package for Social Sciences (SPSS version 10.0); $\mathrm{p}<0.05$ was considered significant.

\section{RESULTS}

\section{Response rate}

Of the 403 traceable subjects, 50.4\% responded. There were no significant differences in gender, mean age, or sport group between respondents and non-respondents $(p>0.05)$. Figure 1 shows the breakdown of percentage of follow up subject who responded by gender and sports category. In relation to the original sample the largest group of responders were female swimmers $(56.6 \%)$, and the lowest group male soccer players $(33.8 \%)$.

\section{Current sport involvement}

Of the 203 respondents, 109 (53.5\%) subjects were still involved in their sport, including individuals who were representing their university and those now coaching their sport. Of the athletes still involved in their sport, 54 (49.5\%) still actively trained, on average 7.28 hours per week (range 1.5-36.0 hours per week). Of the 94 subjects no longer involved in their sport, the majority $(46.7 \%)$ indicated that pressures related to school, university, or work had caused them to drop out of their sport. Fifteen of the subjects $(16.0 \%)$ indicated that they left their sport due to injury. Of these, five were not able to continue to train because of pain in the area injured, while the others found that return to high level competitive sport was too hard following the prolonged recovery necessary after their injury.

\section{Injuries}

Table 1 shows the number of subjects injured between 1990 and 2000. There were no significant differences in the occurrence of an injury between male and female athletes $(p>0.05)$. Ninety three $(45.8 \%)$ of the 203 subjects had suffered from a sports related injury since 1990. No significant difference in the incidence of injury rate was found between those who were $(52.3 \%)$ and those who were not $(42.7 \%)$ still involved in sport $(\mathrm{p}>0.05)$. Of the young athletes not actively training, $38.2 \%$ had sustained a sport related injury compared to $61.1 \%$ of athletes still actively training $(\mathrm{p}<0.05)$.
Table 2 Number of injuries by sport

\begin{tabular}{llrc}
\hline \multirow{4}{*}{ Sport } & \multicolumn{3}{l}{ Number of injuries } \\
\cline { 2 - 4 } & None & One & Two or more \\
\hline Gymnastics & $25(48.1 \%)$ & $14(26.9 \%)$ & $13(25.0 \%)$ \\
Swimming & $41(71.9 \%)$ & $12(21.1 \%)$ & $4(7.0 \%)$ \\
Tennis & $36(50.0 \%)$ & $20(27.8 \%)$ & $16(22.2 \%)$ \\
Soccer & $8(36.4 \%)$ & $5(22.7 \%)$ & $9(40.9 \%)$ \\
\hline \multicolumn{4}{l}{ Values are number (percentage of sample). } \\
\end{tabular}

\section{Relation between sport and injury}

Significantly more soccer players $(63.6 \%)$ sustained sports injuries, with swimmers sustaining relatively few sports injuries $(28.1 \%)$ (table 1 ). Tennis players had significantly more upper limb injuries $(p<0.05)$, soccer players had significantly more lower limb injuries $(p<0.05)$, and gymnasts had significantly more back injuries $(p<0.05)$ than the other sports.

When multiple injury rates were compared, the contrast between swimming and soccer was even more pronounced (table 2): more than five times the number of soccer players sustained two or more injuries compared to swimmers $(\mathrm{p}<0.05)$.

\section{Relation between performance success and injury} Of the 109 subjects still involved with their sport, 8 (7.3\%) competed at international level, 6 (5.5\%) at national level, 25 $(22.9 \%)$ for their region or county, and the remaining $64.3 \%$ described themselves as recreational athletes. The incidence of injury was significantly different between levels of sports involvement (fig 2). Injury occurrence in athletes competing at international and regional/county level was higher, $87.5 \%$ and $64.0 \%$ respectively, than those who competed at national $(16.7 \%)$ or recreational level $(47.1 \%)(p<0.05)$.

Occurrence of injury for those athletes succeeding (semifinals or finals) at the different levels of competition confirms these trends, with 50\% more injuries among athletes who succeeded at the international level compared to those who succeeded at recreational, regional/county, and national levels $(\mathrm{p}<0.05)$.

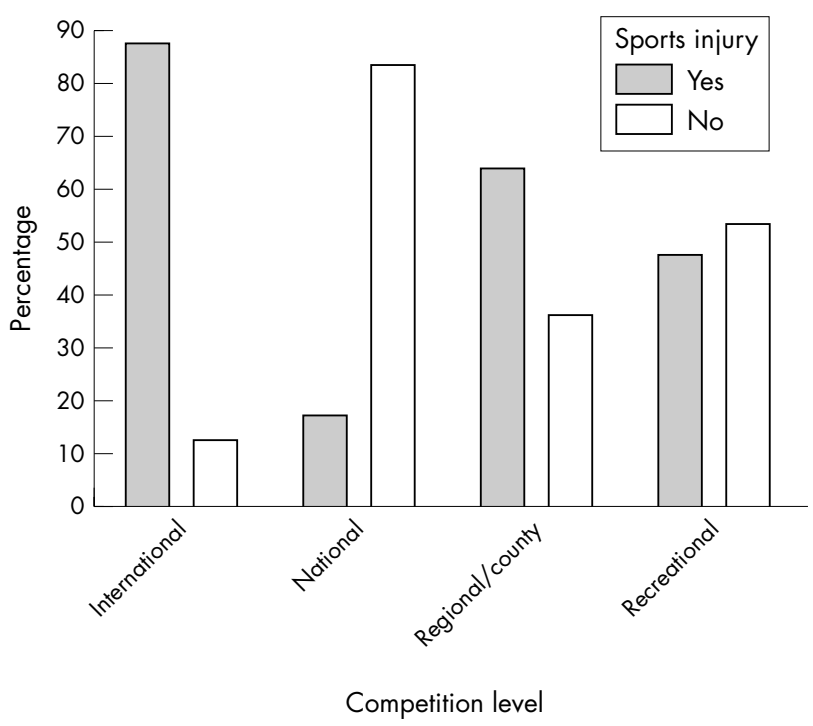

Figure 2 Occurrence of injury by level of competition. 


\section{DISCUSSION}

In this follow up study of intensively trained elite young athletes 10 years after they were last observed, we detected no significant difference in the age, sex, and sport distribution between respondents, non-respondents, and those who remained untraceable. In the present study, young athletes competing and succeeding at international level had significantly higher injury rates than those competing at club, regional/county, or national level, a likely consequence of the intensity and duration of training necessary to compete at high level even at this age. There were no significant differences when comparing gender with occurrence, site, and type of injury, and performance success. Soccer players showed the highest and swimmers reported the lowest overall injury rates. The pattern of injury among sports has not changed significantly when compared with those of the original TOYA study. ${ }^{45}$ Also, injury rates in the young athletes originally recruited in the TOYA study were greater in contact than in non-contact sports. ${ }^{7}{ }^{17}$ Performance success was significantly related to injury rates, possibly linked to the intensity and duration of training. The injury rates in elite young athletes are relatively low, ${ }^{4}$ as they may be naturally gifted, suffering fewer injuries than less successful athletes. ${ }^{18} 19$

The original TOYA study was a prospective longitudinal study, while the present follow up study was retrospective. Although this type of study does not hold the benefits of a prospective study, the results are given further validity by the commitment of the young athletes involved in the original study. However, this does imply that a large number of less severe injuries are recorded. ${ }^{17}$

A limitation of the present study is intrinsic in its nature. Given the long time lag between the original TOYA study and the present investigation, it was inevitable that a large proportion of the young athletes would have moved from their original address. Although age and sex distribution are not different between responders and non-responders, we do not know whether our study population is biased in terms of lower injury rate. This would obviously lead to an underestimation of the effects of intensive training in this population of elite young athletes. Unfortunately, we have no means to control for this.

The TOYA study included only elite young athletes chosen by their coaches. Therefore, selection bias might have been introduced. However, regional and national coaches recruited the subjects, and the final sample population was selected at random, thus minimising any initial bias. A larger sample size would have increased the power of the study, but the number of subjects recruited for the original TOYA study clearly limited the number used in the present investigation. No control group (subjects of similar ages not involved in intensive sports training) was recruited for the original TOYA study. Hence, no growth or injury comparisons could be made between those who were involved in intensive training at a young age and those who were not. However, as most of the subjects originally lived within a 250 mile radius of London, and the present study was performed in another part of the UK, almost 600 miles from London, a postal questionnaire was the most practical method of administering the questionnaire, though semi-structured interviews may have yielded a more complete picture. ${ }^{16}$ Although the present study relies on recall of events, elite young athletes are extremely committed to their health and performance. ${ }^{4}{ }^{13} 15$ A sporting injury to an elite young athlete is a major event, and details of the cause, treatment, and recovery time will be remembered. Thus, recall bias was not thought to be a major problem.

In conclusion, elite young sport performers who continued to train are at a greater risk of musculoskeletal injury than those who did not. The injuries sustained, though not serious, may interfere with the sporting career of an elite young athlete.

\section{Authors' affiliations}

N Maffulli, Keele University School of Medicine, UK

A D G Baxter-Jones, University of Saskatchewan, Canada

A Grieve, University of Aberdeen Medical School, UK

Competing interests: none declared

Correspondence to: Prof. N Maffulli, Department of Trauma and Orthopaedics, Keele University School of Medicine, Thornburrow Drive, Hartshill, Stoke on Trent ST4 7QB, UK; osa14@keele.ac.uk

Accepted 2 November 2004

\section{REFERENCES}

1 Armstrong N, van Mechelen W, eds. Paediatric exercise science and medicine. Oxford University Press, 2000:1-617.

2 Naughton G, Farpour-Lambert N, Carlson J, et al. Physiological issues surrounding the performance of adolescent athletes. Sports Med 2000;30:309-25.

3 Maffulli N, Helms P. Controversies about intensive training in young athletes. Arch Dis Child 1988;63:1405-7.

4 Baxter-Jones A, Maffulli N, Helms P. Low injury rates in elite athletes. Arch Dis Child 1993;68:130-2.

5 Maffulli N. Intensive training in young athletes, the orthopaedic surgeon's viewpoint. Sports Med 1990;9:229-43.

6 Bass S. The prepubertal years. Sports Med 2000;30:73-8.

7 Reider B. Sports medicine: the school age athlete. Philadelphia: Saunders, 1996: 1-232.

8 Cheng JC, Leung SS, Lee WT, et al. Determinants of axial and peripheral bone mass in Chinese adolescents. Arch Dis Child 1998;78:524-30.

9 Cheng JC, Maffulli N, Leung SS, et al. Axial and peripheral bone mineral acquisition: a 3-year longitudinal study in Chinese adolescents. Eur J Pediatr 1999; 158:506-12.

10 Morris F, Naughton G, Gibbs J, et al. Prospective ten-month exercise intervention in premenarcheal girls: positive effects on bone and lean mass. J Bone Miner Res 1997;12:1453-62.

11 Baxter-Jones A. Growth and development of young athletes. Sports Med 1995;20:59-64.

12 Baxter-Jones AD, Maffulli N. Intensive training in elite young female athletes. Effects of intensive training on growth and maturation are not established. Br J Sports Med 2002;36:13-15.

13 Baxter-Jones A, Helms P. Effects of training at a young age: a review of the Training of Young Athletes (TOYA) study. Paediatr Exerc Sci 1996;8:310-27.

14 Baxter-Jones A, Helms P, Maffulli N, et al. Growth and development of male gymnasts, swimmers, soccer and tennis players: a longitudinal study. Ann Human Biol 1995;22:381-94.

15 Maffulli N, King JB, Helms P. Training in elite young athletes (the Training of Young Athletes (TOYA) study): injuries, flexibility and isometric strength. Br J Sports Med 1994;28:123-36.

16 Bennett AE, Ritchie K. Questionnaires in medicine-a guide to their design and use. London: Oxford University Press, 1975.

17 Caine C, Caine D, Lindner K, eds. Epidemiology of sports injuries. Human Kinetics Publishers, 1996: 1-548.

18 Maffulli N. At what age should a child begin to undertake regular continuous exercise at moderate or high intensity? Br J Sports Med 1998;32:298.

19 Maffulli N, Baxter-Jones A. Common skeletal injuries in young athletes. Sports Med 1995; 19:137-49. 